\title{
48
}

\section{A REQUIREMENTS SPACE FOR GROUP-WORK SYSTEMS}

\author{
John McCarthy 1 , Peter Wright ${ }^{2}$ and Michael Harrison ${ }^{2}$ \\ 1Department of Applied Psychology \\ University College Cork \\ Cork, Ireland \\ 2Department of Computer Science \\ University of York \\ Heslington, York, UK \\ Y01 5DD \\ Contact. email mccarthyj@iruccvax.ucc.ie Fax +35321270439
}

KEY WORDS: Computer supported cooperative work (CSCW); Context; Group-work; Organisation; Requirements analysis; Responsibility; Roles; Tasks.

\begin{abstract}
Design and evaluation of systems is facilitated by a comprehensive understanding of requirements. The space within which requirements for group-work systems are considered is of ten limited to negotiated forms of work organisation. This fails to capture requirements for group-work in which organisation is imposed, not negotiated. In this paper, we develop the requirements space for group-working by examining a work context in which order is mainly imposed. The result is a characterisation of the requirements space in terms of three continua group-work interdependency, local to global organisation, and static to dynamic allocation - and an overarching factor, responsibility.
\end{abstract}

\section{INTRODUCTION}

The design and evaluation of systems is facilitated by a comprehensive understanding of requirements. The design of systems to support group-working has generally been informed by analysis of a limited set of tasks, which emphasise cooperation and negotiated order. Analysis is often moot with respect to the organisational context in which tasks are performed. Generalisation from limited empirical analysis has led to an overemphasis of particular factors and processes and neglect of others, the result of which is an underdeveloped requirements space. Our aim in this paper is to develop the requirements space for group-working, by exploring a distinctive work context which emphasises responsibility and accountability.

There are two 'givens' or primitives in all accounts of the organisation of group-working: tasks and roles. In one sense, tasks and roles are simply abstractions across a myriad of situations, which have proved useful in describing and theorising group-working. In another, it is not always clear from the ways in which these constructs are used, that their complexity or the complexity of their interrelationship is well understood.

For groups to work effectively there are two requirements: one is that there is a shared understanding of the work to be done; the other is that there is an agreed procedure for completing the work. In short, effective group-work requires a collective view of both task(s) and group. Group theory represents these requirements in terms of task structure and role structure. Task structure refers to the group's perception of the rules, relating to task decomposition and sequencing, to be followed in order to accomplish their goal. For example, in building a house the walls have to be built before the roof can be erected, but roof erection and door hanging can be carried out in parallel. These task units and orderings reflect both the group's representation of the work and environmental constraints or work context. Role structure refers to the group's perception of the behaviour that can be expected of a person filling a position in a group. For example, the bricklayer, plasterer, and roofer will be expected to perform different parts of the 
work. As the performance of tasks or parts of tasks can be identified with positions in this way, task structure and role structure are highly interrelated.

Although most group theorists and group application designers accept task and role as fundamental to the analysis of group-working, there is a debate in group theory which is often not reflected in the computer supported cooperative working (CSCW) literature. The debate concerns the process of 'structuring' tasks and roles, with one side of the argument emphasising the emergence of tasks and roles from interaction, and the other emphasising their imposition from outside the group. The accepted position in CSCW is that they emerge, they are negotiated in situ. For example, the Communication Structure and Role Structure in COSMOS (Bowers and Churcher, 1988) is configured by participants before they engage in the task. In Coordinator, roles emerge from a public process of making commitments. Finally, the Amsterdam Conversation Environment (Dykstra and Carasik, 1991) claims to provide an environment for work but allows the work group to devise their own structures. These designs reflect a dominant ideology rather than an empirically well founded understanding of group-working.

The empirical analysis which drives requirements analysis for many CSCW systems involves examination of a limited set of tasks, such as collaborative writing or conferencing. Moreover they are carried out in the one organisational context, the research laboratory. Open-ended tasks, carried out by peers who can decide whether to engage or not, lend themselves to an analysis of the organisation of group-work which emphasises negotiated order. There are many group-work contexts in which non-peer interaction is the norm and group structure is imposed, which for political or legal reasons are unlikely to change. Our argument is not that democratised structuring is not desirable, rather that there are work contexts in which it is not a realistic option now, and that requirements analysis in such situations is lacking. Such a work context exists on the commercial flight deck, where task and role structures are quite complex and where a simplified analysis of work organisation will be found wanting. As failure to explore a range of work contexts results in a very limited view of the requirements space, our aim is to complement requirements work already done on peer group-working by examining aspects of work on a flight deck.

\section{GROUP-WORK ON THE FLIGHT DECK}

The example we develop here is taken from a description of group-work on NASA 900, a simulated flight from Los Angeles to Sacramento, presented in Palen (1992). The flight was flown by a real air crew. Flight time was approximately one hour. The flight crew consisted of three members: a captain, first officer $(\mathrm{F} / \mathrm{O})$, and second officer $(\mathrm{S} / \mathrm{O})$. Part of the simulated flight involved responding to a fuel leak, a flight-threatening situation. A simple task structure for diagnosing the fuel leak problem, the first step in recovery, can be captured in a few lines of hierarchical task analysis as in figure 1.

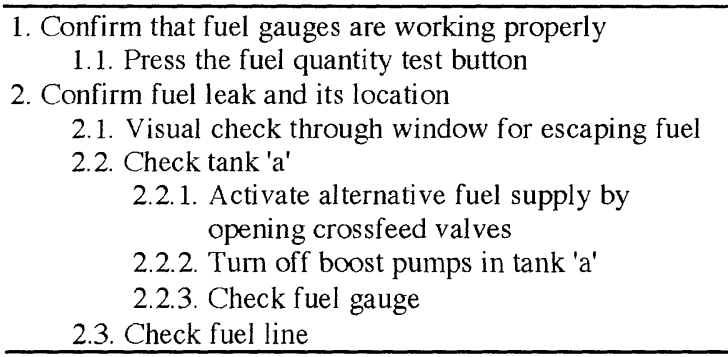

Figure 1. Hierarchical task analysis for diagnosing the fuel leak problem

In all modern aircraft, such tasks are made quite explicit and are recorded on the flight deck in text form as a set of procedures for the crew to follow. On a modern electronic flight deck like the Airbus A320 they would be presented electronically in text formats. In a more traditional cockpit like the NASA 900,727 cockpit, the written procedures are contained in a manual often referred to as the quick reference handbook $(\mathrm{QRH})$. In principle, the role structure is also very simple and well prescribed. One of the second officer's roles, for example, is to monitor engine and fuel system status. He has all of the fuel gauges in front of him, and the controls for the fuel valves and pumps are within easy reach. Both task and role structure are simple and prescribed by formal division of labour, manuals, and the environmental constraints of the cockpit.

Classical analysis would suggest that the fuel leak diagnosis is a simple task to be carried out by the second officer. However, in the case of NASA 900 , it becomes a group problem solving activity. Having performed the tasks outlined in figure 2 , with the 
associated outcomes, the second officer involves the rest of the crew in diagnosing the fuel leak.

\begin{tabular}{ll}
\hline Check to see that gauges are working & yes \\
Turn number 3 boost pumps off & yes \\
Feed number 3 engines from pump tank 1 & yes \\
Check to see if fuel is still being lost from & \\
number 3 tank & yes \\
\hline
\end{tabular}

Figure 2: Tasks carried out by second officer before initiating group-work

The second officer's decision to make the work collaborative means that he accrues to himself extra tasks, namely informing the other members of the crew of what he has seen, what diagnoses he has considered and what actions he has carried out, as can be seen in figure 3 .

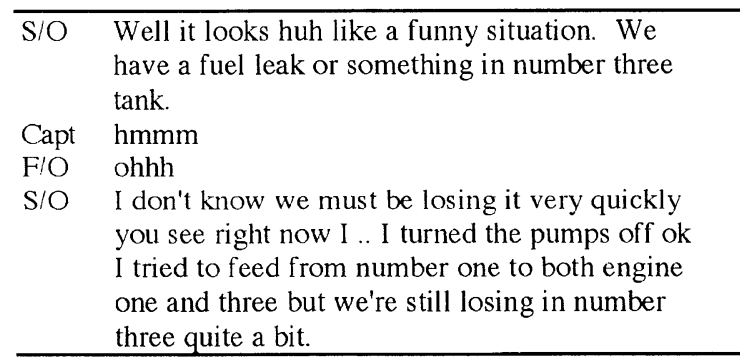

Figure 3. Extract from flight deck communications of NASA 900 , illustrating the information-sharing activities initiated by the second officer.

Other members of the crew also incur additional tasks as a consequence of the second officer's decision. In particular, the captain has to use his knowledge of the fuel system and associated operating procedures to cross-check the second officer's actions, as can be seen in figure 4 .

\begin{tabular}{|c|c|}
\hline $\begin{array}{l}\mathrm{S} / \mathrm{O} \\
\mathrm{Capt}\end{array}$ & $\begin{array}{l}\mathrm{k} \text { this is kind of unusual I don't know if we have a } \\
\mathrm{hmm}\end{array}$ \\
\hline Capt & $\begin{array}{l}\text { so you shut off both boost pumps right you were } \\
\text { losin }\end{array}$ \\
\hline $\mathrm{S} / \mathrm{O}$ & that's right yeah \\
\hline ATIS & (interrupts again, $\mathrm{S} / \mathrm{O}$ reaches up to turn it off) \\
\hline Capt & ok \\
\hline $\mathrm{S} / \mathrm{O}$ & what I tried to do I - \\
\hline Capt & do they test \\
\hline $\mathrm{S} / \mathrm{O}$ & $\begin{array}{l}\text { balance and right now we're still losing from } \\
\text { number three tank you see ...two boost pumps off }\end{array}$ \\
\hline
\end{tabular}

Figure 4. Extract from flight deck communications of NASA 900 , in which the captain cross-checks the second officer's actions.
With reference to group-working, what is happening during the phase of the diagnostic work captured in figures 3 and 4 ? We can conclude from the second officer's uncertainty - "this is kind of unusual I don't know if we have a" - that, having carried out the standard procedures, he feels unable to diagnose the fuel leak alone. Therefore, he engages the rest of the crew in a group task, an action which carries with it the obligation to develop a shared understanding of the task. It could be argued that, in figures 3 and 4, we are observing the initiation of that process of context sharing, to facilitate a shared understanding of the task and the coordination of group activities. Furthermore, given the "unusual" nature of the second officer's observations it has now become a case of negotiating an appropriate understanding of the task rather than following standard operating procedures.

To recap: The goal is to diagnose the fuel leak. The original representation of task and role structure was relatively simple and well prescribed. However, following unusual results while executing the task using the prescribed procedures, the task needs to be redefined.

Although the captain and second officer take on roles appropriate for the task of redefinition (information sharing roles), there is a sense in which nothing significant happens to the overall role structure. It is clear, from figure 4 , that the captain has responsibility for the flight: he takes command and the second officer assists. Despite the fact that the second officer has more information about the state of the system, there is no sense of him trying to negotiate a broader role for himself in redefining the task. So, while aspects of the roles for the task of redefinition could be said to emerge from the immediate interaction, the roles which do emerge are strongly constrained by the formal division of labour and authority in the cockpit.

To summarise: Whereas task and role structure are largely open for negotiation in collaborative writing, and almost wholly fixed in house building, flying a plane admits limited negotiation, constrained by the imposed formal group structure. Yet, the factors and processes which shape the structure of group-work are similar for all three tasks. It is just that they take on more values than an analysis of open-ended, context-free tasks alone can reveal. These factors constitute the requirements space for groupworking, which is outlined in the next section. 


\section{LOCATING GROUP-WORK IN A REQUIREMENTS SPACE}

In section 1, we identified task and role structure as the basic elements in any approach to understanding the organisation of group-working. In section 2, we demonstrated empirically that they are more complex constructs than might be imagined from an analysis of one type of task alone. To understand their complexity and the complexity of their interrelationships, empirical analysis of a range of tasks is required. Comparison of the tasks already analysed in CSCW, such as collaborative writing, and tasks such as flying a plane offers a rich requirements space. In this section we will outline some of the key dimensions of that requirements space, as a set of continua along which various group-work contexts can be positioned.

\section{Independent - Interdependent}

Group-work can be classified according to whether the tasks and roles are independent of each other or interdependent. The cockpit is a tightly coupled system (Perrow, 1984). This means that a task carried out by one individual produces outcomes which affect the outcomes of other tasks performed by other individuals. For example, a large fuel leak will affect the centre of gravity of an aircraft. Changes to the centre of gravity of an aircraft will affect the way the aircraft handles in flight. Thus, in the fuel leak scenario, the second officer dealing with a fuel leak will affect the pilot's task of flying the aircraft, as the pilot may need to take corrective action to compensate for an 'out of balance' condition.

Interdependency between the pilot's task and the second officer's task means that there is a mutual obligation on these two individuals to share knowledge about the way the aircraft is handling and the state of the fuel system. Figure 3 can be seen as illustrating the second officer discharging his obligation to share knowledge. Note for example the second officer points out that they are "losing it very quickly" which can be taken as informing the pilot that he may require to take corrective action to ensure safe handling of the aircraft. Thus, roles are also highly interdependent.

In contrast with the flight deck context, project work can involve lots of independent work. The site foreman can independently engage a plasterer to plaster the walls and a joiner to deal with doors and windows. The work can be done in parallel but the tasks are totally independent of each other. Collaborative writing introduces a temporal dimension which could lead to a more refined analysis of dependency. As the tasks of writing different sections are quite interdependent, lots of context sharing is required if the paper is to be a coherent whole. However, the general lack of a temporal constraint appears to loosen the coupling between tasks and roles.

\section{Local - Global}

This dimension refers to the extent to which the actual group-work and its organisation is locally or globally structured. Bowers and Churcher (1988) presented an interesting discussion of this dimension with respect to messaging. We will broaden it a little here.

As we demonstrated in section 2, work on the flight deck can be highly prescribed by manuals and procedures, which describe who should be doing what and when, and which have been written by a flight technical officer, who is not on the flight deck when the work is performed. This is referred to as global structuring of tasks and roles.

Work on the flight deck is cognitively and socially complex. Moreover, it may require time critical and safety critical decisions in situations where members of the crew don't agree. This is reflected in the institutional division of labour on the flight deck. Put simply, the person holding the position of flight commander has the final say. This institutional division of labour between commander, flying officer, and second officer, specifies the kind of knowledge, background, and expertise that can be associated with a person holding a particular position. This clarifies for all members of the crew what they should be able to expect from the others. Note for instance, in figure 4 , how much knowledge the captain has of the fuel system and the second officers' job.

The organisation of the work of collaboratively writing a paper is generally quite different from the global organisation outlined above. The task is defined by the group performing it. Role allocation is locally negotiated or emerges from ongoing interaction. The aim in writing a paper is not to control a process but to be creative and interesting, an objective which would most likely be stifled by the imposition of a task or role structure. Of course 
this analysis only applies when paper writing is carried out amongst peers. One can envisage circumstance where a research manager might allocate tasks and roles in even this task.

This discussion glosses over two further aspects of the organisation of group-work, which suggests two other dimensions for the requirements space, which need further work. Space permits no more than a mention of them here. The first is formality informality, a dimension which would characterise the regularity or uniformity of work organisation. For instance, because the individuals who make up a crew change, work organisation on the cockpit is formalised in written procedures and in the positions held. This allows crew member who have not previously worked together to know, from the outset, what to expect of other members. In contrast, the research manager might allocate tasks and roles on one writing project and not on another. The second dimension is explicit - implicit. This refers to the extent to which work organisation is made public. Some critiques of Coordinator, for instance, argued that its failing was in making the process of commitment-making explicit. Clearly these two dimensions relate in some ways to the local - global dimension. Therefore further work is required before deciding whether they were dimensions in their own right or refinements of the local - global dimension.

\section{Static - Dynamic}

This dimension refers to the extent to which tasks and roles and their allocation remain the same or change across situations. In the analysis of work on the flight deck in section two, we say that when the fuel leak task seemed to be changing, the crew members involved seemed to take on some new roles but without giving up their existing ones. The captain became a mentor and advisor but he was clearly still captain and commander.

In fact the cockpit is an interesting example as even its global role allocation procedures recognise the need for some flexibility. Within the cockpit roles have both dynamic and static aspects. For example, the naming of the three people on the flight deck as captain (or commander) first officer, and second officer, reflects a set of relatively static roles. Whoever is the commander will make decisions about flight safety and mission effectiveness. The role of commander would not change unless he became incapacitated, when this role would pass to the first officer.

In contrast, the role of pilot changes dynamically throughout a flight. Both the captain and the first officer are be fully trained and skilled pilots. Although their titles do not change during a flight, their roles do, as they 'take turns' actually flying the plane. The pilot flying the plane is the handling pilot. The other pilot, the non-handling pilot, is responsible, among other things, for navigation and communications. This fluidity of roles is reflected in the fact that the workstations of the two pilots are more or less identical. In contrast, the role of flight engineer does not alternative between individuals. This is also reflected in the layout of the design of the aircraft workstations. The second officers workstation is not equipped for flying the plane, and the individual is not a pilot.

While people may change roles dynamically within a flight, the roles themselves are static. There must be a handling pilot, a non-handling pilot, and a second officer. This static role allocation serves as a means of ensuring that in times of high workload there is enough manpower available to carry out the tasks required. For example, we have seen that if the fuel leak is serious, diversions will be required. This involves communications outside of the cockpit, a task fulfilled by the non-handling pilot. Adjustments to and monitoring of the handling of the aircraft will have to attended to. This will be the job of the flying pilot. Fuel use will have to be re-calculated and rebalanced, the job of the second officer.

The situation in collaborative writing is generally more fluid. It would be reasonable to expect that anybody writing a journal paper could write, edit, control versions, and so on. However it becomes a little more like the cockpit when the paper is interdisciplinary and the psychologist feels that he can't 'do the computer science bit'. Then everybody would be expected to write and edit, but people from different disciplines might be required to write first drafts of different sections.

\section{Responsibility}

Responsibility doesn't constitute a dimension as such, but it is a critical factor in differentiating between collaborative writing and group-work on the flight deck and may have implications for the requirements space. Some researchers have treated responsibility as part of the role structure - that is to 
say a person in a position is responsible for the work associated with that position - we have used 'legitimate expectation' in place of responsibility in this context. It seems to us that responsibility operates on a number of different levels. It speaks to the 'world' in which the group-work is performed rather than the internal organisation of the group-work per se, though it may be one of the most influential factors in shaping that organisation. It has organisational, legal, and moral dimensions, to name a few.

On the flight deck of a commercial aircraft, it is an individual, the commander (in the NASA 900 case the captain), who has a legally defined responsibility for the safety of the flight. Negligence of this responsibility can cost him his job or a large fine. Cooper (1991), for example, reports a case in which a commander was prosecuted and fined $£ 2,000$ with $£ 1,500$ costs for low flying. Such accountability may impose a constraint which is strong enough to overwhelm all other considerations when weighing up the costs and benefits of collaboration. The commander 'carries the can' and therefore must make and own any decisions which have safety consequences. The commander cannot negotiate away his responsibility for the safety of the flight, for instance. This affects not only his behaviour on the flight deck but also the behaviour of his colleagues. The second officer in deciding to make the fuel leak problem a shared task may have been affected by his awareness that this was a flight safety issue and the commander would need to know.

The responsibilities associated with writing a scientific paper are different. If the paper fails to be accepted or meet a deadline, the authors are jointly responsible and they are normally not accountable to a higher authority. However, it could be argued that scientific articles attract ethical responsibilities. For much scientific work, researchers are responsible to ethical committees.

\section{CONCLUSIONS}

Our aim in this paper was to develop the requirements space for group-working. The first step was to identify task and role structure as the basic elements in any approach to understanding the organisation of group-working. We then explored the organisation of group-working - task and role structuring - on a flight deck, a work context which differs radically from many examined in the CSCW literature. Based on these conceptual and empirical analyses, we have described the following dimensions in an attempt to characterise the requirements space for group-working, as a set of continua along which various group-work contexts can be positioned: task and role interdependence; local to global control of work organisation; and the stability of role allocation. We suggested a number of other dimensions for future work: the temporal dimension as it relates to task interdependence; and the formality and explicitness of the control of work organisation. Finally we raised the issue of responsibility as an external constraint on groupwork performance, which needs more detailed consideration.

\section{REFERENCES}

Bowers, J. and Churcher, J. (1988). Local and global structuring of computer mediated communication: developing linguistic perspectives on CSCW in COSMOS. In Proceedings of the Conference on Computer Supported Cooperative Work (CSCW'88), 125-139. ACM Press: New York

Cooper, G. (1991). Safety and the criminal law. Aerospace, July 1991, 14-15.

Dykstra, E. A. and Carasik, R. P. (1991). Structure and support in cooperative environments: the Amsterdam Conversation Environment. International Journal of ManMachine Studies, 34, 419-434.

Palen, L. (1992). Distributed cognition in an airline cockpit: the second officer's panel as a communicative resource. Unpublished Thesis. Distributed Cognition Laboratory, University of California, San Diego.

Perrow, C. (1984). Normal accidents: Living with high risk technologies. New York: Basic Books.

Winograd, T. and Flores, F. (1986). Understanding computers and cognition: a new foundation for design. Reading, MA: Addison-Wesley. 